\title{
FAKTOR DETERMINAN KEJADIAN PRA-SINDROM METABOLIK PADA DOSEN DAN TENAGA KEPENDIDIKAN DI INSTITUSI PENDIDIKAN TINGGI
}

\author{
*Titi Indriyati ${ }^{1)}$, Ilah Muhafilah ${ }^{2)}$, Fatimah $^{3)}$ \\ Program Studi S1 Keperawatan, Fakultas Kesehatan, Universitas Mohammad Husni Thamrin \\ Correspondence author: titi.indri@gmail.com, Jakarta, Indonesia
}

DOI: https://doi.org/10.37012/jik.v12i1.179

\begin{abstract}
ABSTRAK
Pra-sindrom metabolik (Pra-SM) adalah keadaan individu yang mengalami obesitas sentral (lingkar pinggang pria $\geq 90 \mathrm{~cm}$, wanita $\geq 80 \mathrm{~cm}$ ) disertai satu indikator sindrom metabolik yaitu tekanan darah $\geq 130 / 85 \mathrm{mmHg}$ atau dalam pengobatan antihipertensi atau pernah didiagnosis hipertensi oleh tenaga kesehatan. Bagaimanapun juga, pra-SM merupakan indikator skrining yang baik untuk mengidentifikasi masalah penyakit tidak menular di tempat bekerja, karena produktifitas pekerja harus didukung oleh kondisi kesehatan yang optimal. Tujuan penelitian ini untuk mengetahui faktor determinan pra-SM pada pekerja (dosen dan tenaga kependidikan) di Universitas MH. Thamrin. Metode yang digunakan dalam penelitian ini yaitu Desain cross sectional, terhadap 128 responden yang diperoleh dari metode total sampling. Analisis dilakukan pada data primer meliputi univariat, uji chi square dan analisis multivariat regresi logistik ganda. Prevalens pra-SM sebesar 38,3\%; didominasi oleh: pria (47,9\%), berusia $>35$ tahun (44,9\%), dan mengalami kegemukan $(55,9 \%$.). Faktor determinan yang paling berisiko terhadap pra-SM adalah: umur >35 tahun (OR: 3,11; 95\%CI: $1,18-8,23)$; kegemukan (OR: 5,02; 95\%CI: 2,20 11,47); jenis kelamin pria (OR: 2,02; 95\%CI: 0,87 - 4,67) dan pendapatan <UMR DKI Jakarta tahun 2019 (OR: 1,91; 95\%CI: 0,79 - 4,65). Rekomendasi perlunya dilakukan program pencegahan primer yaitu pemeriksaan kesehatan rutin bagi pekerja untuk deteksi dini dan menurunkan risiko pra-SM.
\end{abstract}

Kata kunci: Pra-Sindrom Metabolik, Faktor, Pekerja.

\section{ABSTRACT}

Pre-metabolic syndrome (Pre-SM) is a condition of individuals who have central obesity (men's waist circumference $\geq 90 \mathrm{~cm}$, women $\geq 80 \mathrm{~cm}$ ) accompanied by one indicator of metabolic syndrome that is blood pressure $\geq 130 / 85 \mathrm{mmHg}$ or in antihypertensive treatment or have been diagnosed with hypertension by health workers. However, pre-SM is a good screening indicator to identify the problem of non-communicable diseases in the workplace, because worker productivity must be supported by optimal health conditions. The purpose of this study was to determine the pre-SM determinant factors in workers (lecturers and education staff) at MH University. Thamrin. The method used in this study is cross sectional design, of 128 respondents obtained from the total sampling method. Analyzes were performed on primary data including univariate, chi square test and multivariate analysis of multiple logistic regression. Pre-SM prevalence of 38.3\%; dominated by: men (47.9\%), aged> 35 years (44.9\%), and overweight (55.9\%). The determinants most at risk for pre-SM are: age> 35 years (OR: 3.11; 95\% CI: 1.18 8.23); obesity (OR: 5.02; 95\% CI: 2.20 - 11.47); male sex (OR: 2.02; 95\% CI: 0.87 - 4.67) and revenue <UMR DKI Jakarta in 2019 (OR: 1.91; 95\% CI: 0.79 - 4.65). Recommendations on the need for a primary prevention program are routine health checks for workers for early detection and reducing pre-SM risk.

Keywords: Metabolic Pre-Syndrome, Factors, Workers. 


\section{PENDAHULUAN}

Dalam laporan WHO tahun 2018 disebutkan bahwa penyakit tidak menular (PTM) telah menyebabkan kematian sebesar $71 \%$ dari kematian global atau sekitar 41 juta orang per tahun. Sedangkan di negara yang berpenghasilan rendah dan menengah, telah terjadi lebih dari 85\% kematian 'prematur' akibat PTM pada penduduk berusia 30 - 69 tahun dan setiap tahun 15 juta orang meninggal karena PTM. Tingginya angka kematian akibat PTM juga terjadi di Indonesia yaitu sebesar 73\% (WHO, 2018).

Prevalensi PTM di Indonesia mengalami peningkatan seperti: kanker, strok, penyakit ginjal kronis, diabetes dan hipertensi. Riset Kesehatan Dasar tahun 2018 telah melaporkan bahwa terdapat peningkatan jika dibandingkan dengan tahun 2013. Prevalensi kanker meningkat dari $1,4 \%$ menjadi $1,8 \%$, strok dari $7 \%$ menjadi $10,9 \%$, penyakit ginjal kronis dari $2 \%$ menjadi $3,8 \%$, hipertensi berdasarkan pengukuran dari $25,8 \%$ menjadi $34,1 \%$. Demikian juga pada diabetes melitus berdasarkan diagnosis dokter terjadi peningkatan dari $1,5 \%$ menjadi $2 \%$ (Kemenkes RI, 2018).

Bersamaan dengan meningkatnya prevalensi PTM tersebut tentunya meningkat pula risiko kejadian sindrom metabolik (SM). Berdasarkan defisnisi dari NCEP-ATP III (The National Cholesterol Education Programme Adult Treatment Panel III) bahwa SM untuk Asia adalah keadaan klinis pada seseorang yang memenuhi paling sedikit tiga dari lima komponen faktor risiko yaitu obesitas sentral (lingkar pinggang laki-laki $\geq 90 \mathrm{~cm}$ dan perempuan $\geq 80 \mathrm{~cm}$ ), kadar kolesterol HDL rendah (laki-laki $<40 \mathrm{mg} / \mathrm{dL}$ dan perempuan $<50 \mathrm{mg} / \mathrm{dL}$, atau dalam pengobatan), hipertrigliserida serum $(\geq 150 \mathrm{mg} / \mathrm{dL}$ atau dalam terapi), peningkatan tekanan darah ( $\geq 130 / 85 \mathrm{mmHg}$ atau dalam terapi), dan glukosa darah puasa ( $\geq 110 \mathrm{mg} / \mathrm{dL}$ atau dalam terapi) (Chackrewarthy et al., 2013).

Salah satu kelompok masyarakat yang perlu mendapatkan perhatian terhadap perkembangan SM adalah para pekerja di perkantoran. Hal ini dikarenakan aktivitas fisik di kantor semakin berkurang, hanya 6,5\% orang dewasa yang melakukan aktivitas fisik sambil bekerja. Jika dibandingkan dengan pekerja di era 1960-an, pekerja yang pekerjaannya membutuhkan aktivitas fisik, menurun dari angka 50\% menjadi $20 \%$ (Church et al., 2011). Beberapa faktor perilaku pekerja yang berkaitan dengan SM, antara lain: pekerja yang berolahraga lebih banyak dan waktu tidur 8 jam memiliki risiko yang lebih rendah untuk mengalami SM (Johnson et al., 2015). Adapun faktor lain yang dapat 
meningkatkan risiko terjadinya SM adalah kebiasaan merokok (OR: 1,55; 95\%CI: 1,092,21) dan minuman beralkohol (OR: 1,44; 95\%CI: 1,06-1,96) (Jeong, 2018).

Kelompok dosen dan tenaga kependidikan pada institusi pendidikan tinggi merupakan kelompok pekerja perkantoran yang memiliki beberapa faktor risiko perilaku seperti yang telah disebutkan di atas. Sebagai kelompok pekerja yang mengelola pendidikan tinggi tentu saja memerlukan fisik yang sehat untuk mendukung pekerjaannya. Berbagai faktor risiko SM harus dapat diidentifikasi atau disadari keberadaannya oleh mereka sehingga munculmya PTM dapat dicegah dan ditanggulangi secara dini. Produktifitas pekerja perlu didukung oleh kondisi kesehatan yang optimal. Kondisi pra-sindrom metabolik (pra-SM) dapat menjadi indikator skrining yang baik untuk mengenali masalah kesehatan khususnya PTM.

Penelitian ini bertujuan untuk mengetahui faktor determinan yang berhubungan dengan kejadian pra-SM pada dosen dan tenaga kependidikan di Universitas MH. Thamrin. Hasil penelitian diharapkan dapat memberikan infromasi untuk menjadi dasar pengembangan program kesehatan yang berkelanjutan dalam rangka mendukung upaya memerangi PTM melalui kegiatan promotif dan preventif di lingkungan kampus.

\section{METODE}

Penelitian ini menggunakan desain cross sectional yang telah dilaksanakan pada Desember 2019 - Januari 2020. Pengumpulan data menggunakan kuesioner yang telah memenuhi kriteria validitas dan reliabilitas. Sehubungan dengan manfaat penelitian yang dikaitkan dengan pengembangan program kesehatan, maka penelitian mengikutsertakan seluruh dosen dan tenaga kependidikan di Universitas MH. Thamrin Jakarta Timur. Jumlah keseluruhan total sampel adalah \pm 180 orang, namun respon rate hanya mencapai 71\% (128 responden dari 180 orang). Beberapa alasan ketidakikutsertaan mereka adalah karena kondisi fisik yang tidak sehat, sedang menjalankan tugas profesinya dan menolak untuk menjadi responden. Penjelasan sebelum persetujuan (PSP) tetap dilakukan oleh tim peneliti agar responden lebih mengerti tentang manfaat keikutsertaannya dalam penelitian yang kemudian dilegalkan dengan penandatanganan informed consent.

Peneliti menggunakan definisi pra-SM yaitu individu yang memenuhi kriteria obesitas sentral atau lingkar pinggang $\geq 90 \mathrm{~cm}$ (pria) dan $\geq 80 \mathrm{~cm}$ (wanita), tekanan darah $\geq 130 / 85$ 
$\mathrm{mmHg}$ atau sedang dalam pengobatan antihipertensi atau pernah didiagnosis hipertensi oleh tenaga kesehatan (Shuto et al., 2015; Tan et al., 2016). Pengukuran tekanan darah dilakukan menggunakan alat Sphygmomanometer digital yang telah dikalibrasi. Obesitas sentral diukur menggunakan pita ukur dengan tingkat ketelitian $1 \mathrm{~mm}$ pada lingkar pinggang responden oleh tim enumerator terlatih.

Beberapa faktor determinan diukur dengan kuesioner khusus, yaitu pengukuran aktifitas fisik dengan kuesioner dari WHO. Aktifitas fisik dihitung berdasarkan bobot jenis aktivitas fisik dan lama waktu yang digunakan untuk melakukan jenis aktivitas pada masing- masing kegiatan. Pengkategorian aktifitas didasarkan perhitungan secara komposit dari jenis aktifitas dan lama aktifitas (jumlah menit per hari dan jumlah hari per minggu). Aktifitas berat mempunyai bobot 8 kali, aktifitas sedang mempunyai bobot 4 kali, aktifitas ringan mempunyai bobot 2 kali. Data numerik ini selanjutnya dikatagorikan menjadi: kurang aktifitas apabila mempunyai total aktifitas fisik <600 MET dalam 1 minggu.

Pengukuran kualitas tidur menggunakan kuesioner PSQI (The Pittsburg Sleep Quality index). Skor kualitas tidur menggunakan cut off point $=5$ untuk menentukan batasan gangguan tidur (A. Alamri et al., 2019). Sedangkan status kesehatan mental mengadopsi kuesioner dari Kemenkes RI, cut off point $=6$ untuk menentukan skor responden yang kesehatan mentalnya terganggu.

Pengolahan dan analisis data dilakukan dengan menggunakan program paket statistik SPSS ver 20. Pada tahapan analisis data dimulai dengan analisis distribusi frekuensi per variabel (univariat), analisis uji chi square (bivariat) dan besarnya atau kekuatan hubungan ditentukan dari nilai PR (Prevalence Ratio). Tahap akhir dilakukan analisis multivariat dengan mengikutsertakan semua variabel untuk menjelaskan model yang tepat dan sederhana (robust and parsimonious) dalam menggambarkan hubungan faktor determinan dengan kejadian pra-SM pada dosen dan tenaga kependidikan di Universitas MH. Thamrin.

\section{HASIL DAN PEMBAHASAN}

Deskripsi karakteristik responden berdasarkan ukuran antropomertik dalam tabel 1, menjadi dasar untuk menentukan kriteria pra-SM. 
Tabel 1. Distribusi Frekuensi Antropometrik Dan Tekanan Darah Pada Dosen dan Tenaga Kependidikan Universitas MH. Thamrin (n=128)

\begin{tabular}{lcccc}
\hline \multicolumn{1}{c}{ Variabel } & Rata-rata & Minimum & Maksimum & Standar deviasi \\
\hline Lingkar perut $(\mathrm{cm})$ & 91,3 & 65 & 120 & 10,3 \\
\hline Tekanan darah sistolik $(\mathrm{mmHg})$ & 122,3 & 83 & 176 & 16,7 \\
\hline Tekanan darah diastolik $(\mathrm{mmHg})$ & 79,2 & 60 & 114 & 10,8 \\
\hline Berat badan $(\mathrm{kg})$ & 67,6 & 40,7 & 100 & 12,1 \\
\hline Tinggi badan $(\mathrm{cm})$ & 159 & 145 & 177 & 6,9 \\
\hline IMT $\left(\mathrm{kg} / \mathrm{m}^{2}\right)$ & 26,8 & 16,8 & 41,7 & 4,6 \\
\hline & & & Frekuensi $(\mathbf{n})$ & Persentase $(\boldsymbol{\%})$ \\
IMT $($ Indeks Massa Tubuh) & & 59 & 46,1 \\
\hline Berat badan lebih tingkat berat $\left(>27 \mathrm{~kg} / \mathrm{m}^{2}\right)$ & & 24 & 18,8 \\
Berat badan lebih tingkat ringan $\left(25,1-27 \mathrm{~kg} / \mathrm{m}^{2}\right)$ & & 43 & 33,6 \\
Berat badan normal $\left(18,5-25 \mathrm{~kg} / \mathrm{m}^{2}\right)$ & & 2 & 1,5 \\
Berat badan kurang tingkat berat $\left(17-18,4 \mathrm{~kg} / \mathrm{m}^{2}\right)$ & & $\mathbf{1 2 8}$ & $\mathbf{1 0 0}$ \\
\hline Jumlah Total & & & \\
\hline
\end{tabular}

Sumber: Data Primer, 2019.

Tabel 1. Menunjukkan keadaan obesitas sentral dari nilai rerata lingkar pinggang $91,3 \mathrm{~cm}$, artinya gambaran secara umum responden mengalami obesitas sentral. Keadaan hipertensi tidak nampak dalam nilai rerata tekanan darah sistolik $(122,3 \mathrm{mmHg})$ maupun diastolik (79,2 $\mathrm{mmHg})$, namun adanya sejumlah responden yang mengalami hipertensi dapat diidentifikasi dari nilai maksimum sistolik yaitu $176 \mathrm{mmHg}$ dan diastolik yaitu 114 $\mathrm{mmH}$. Ukuran antropometrik yang lain seperti berat badan dan tinggi badan dikonversi menjadi nilai indeks massa tubuh (IMT) untuk memberikan gambaran status obesitas. Obesitas yang dimaksud adalah obesitas umum yang berbeda dengan obesitas sentral namun dapat dikaitkan dengan munculnya risiko SM. Rerata IMT $26,8 \mathrm{~kg} / \mathrm{m}^{2}$ menunjukkan ada risiko kelebihan berat badan dan tampak bahwa hampir separuh responden $(46,1 \%)$ memiliki IMT $>27 \mathrm{~kg} / \mathrm{m}^{2}$, yang dalam katagori IMT untuk orang Indonesia termasuk dalam kelompok berat badan lebih tingkat berat (kegemukan).

Tabel 2. Distribusi Frekuensi Pra-Sindrom Metabolik Pada Dosen dan Tenaga Kependidikan Universitas MH. Thamrin (n=128)

\begin{tabular}{lcc}
\hline Katagori Pra-Sindrom metabolik & Frekuensi (n) & Persentase (\%) \\
\hline Memenuhi kriteria Pra-SM & 49 & 38,3 \\
\hline Tidak memenuhi kriteria Pra-SM & 79 & 61,7 \\
\hline Total & $\mathbf{1 2 8}$ & $\mathbf{1 0 0 , 0}$ \\
\hline Sumber: Data Primer, 2019 & &
\end{tabular}


Prevalens pra-SM pada tabel 2 yaitu sebesar 38,3\% diantara responden yang eligible. Angka ini menunjukkan kejadian pra-SM yang perlu mendapat perhatian untuk diantisipasi agar tidak berkembang menjadi SM. Temuan prevalens pra-SM ini merupakan kondisi kesehatan yang perlu menjadi perhatian, karena SM merupakan faktor risiko utama untuk penyakit kardiovaskular dan diabetes (Negi et al., 2019). Pendekatan manajemen kesehatan di berbagai tatanan layanan kesehatan termasuk instituti tempat bekerja perlu diterapkan, sekurang-kurangnya dalam bentuk skrining diagnosis secara berkala. Seperti pada penelitian di Taiwan terhadap para pekerja yang diobservasi dalam kurun waktu 5 tahun. Penelitian tersebut menjadi program skrining kesehatan karena pemeriksaan kesehatan rutin berkala wajib bagi pekerja di Taiwan. Hasil yang diperoleh adalah perkembangan SM di antara karyawan berusia paruh baya dengan berbasis data tersebut untuk menilai risiko berkembangnya SM. Hasil pengamatan dalam 5 tahun diperoleh kasus baru sebesar 13\% (175 dari 1.384 orang) yang memenuhi kriteria SM (Lin et al., 2010).

Universitas MH. Thamrin memiliki keunggulan program pendidikan bidang kesehatan, sehingga dapat mendukung pengembangan program skrining berkala untuk seluruh dosen dan tenaga kependidikan. Hasil penelitian ini akan menjadi dasar penguatan program tersebut. Upaya kesehatan yang dapat dilakukan adalah pencegahan primer pada individu yang masih sehat dan pengendalian faktor risiko bagi individu yang berisiko.

Selanjutnya, tabel 3 memperlihatkan deskripsi kasus pra-SM pada responden berdasarkan karakteristiknya. Faktor determinan yang bermakna secara statistik dalam hubungannya dengan kejadian pra-SM adalah umur (PR: 1,95; 95\% CI: 1,05 - 3,61). Selanjutnya variabel jenis kelamin yaitu wanita lebih banyak (80 orang dari 128), namun proporsi praSM lebih besar pada pria (47,9\%); PR: 1,47 (95\%CI: 0,96 - 2,27) sehingga responden pria berisiko 1,5 kali lebih tinggi untuk mengalami pra-SM. Perbedaan proporsi pra-SM berdasarkan katagori kegemukan menunjukkan risiko pra-SM sebesar 1,74 kali lebih tinggi pada mereka yang mengalami kegemukan daripada yang tidak gemuk. Hasil ini menunjukkan nilai yang bermakna secara statistik (95\% CI: 1,27-2,39). Sejalan dengan itu, status sosial ekonomi menunjukkan perbedaan proporsi antara kelompok dengan tingkat pendapatan rendah dan tinggi meskipun hubungan tidak bermakna secara statistik (PR: 1,33; 95\% CI: 0,85-2,06). 
Tabel 3. Deskripsi Kejadian Pra-SM Berdasarkan Karakteristiknya

\begin{tabular}{|c|c|c|c|c|}
\hline \multirow[t]{2}{*}{ Variabel } & \multirow{2}{*}{$\begin{array}{l}\text { Frekuensi } \\
\text { (n) }\end{array}$} & \multicolumn{2}{|c|}{$\begin{array}{c}\text { Pra-Sindrom Metabolik } \\
(\mathbf{n}(\%))\end{array}$} & \multirow{2}{*}{$\begin{array}{c}\text { PR } \\
(95 \% \mathrm{CI})\end{array}$} \\
\hline & & Ya (49) & Tidak (79) & \\
\hline \multicolumn{5}{|l|}{ Umur (tahun) } \\
\hline$>35$ (dewasa akhir - lansia) & 89 & $40(44,9)$ & $49(55,1)$ & $1,95 *$ \\
\hline$\leq 35($ remaja - dewasa awal $)$ & 39 & $9(23,1)$ & $30(76,9)$ & $(1,05-3,61)$ \\
\hline \multicolumn{5}{|l|}{ Status Pegawai } \\
\hline Dosen & 63 & $26(41,3)$ & $37(58,7)$ & 1,17 \\
\hline Tenaga Kependidikan & 65 & $23(35,4)$ & $42(64,6)$ & $(0,75-1,81)$ \\
\hline \multicolumn{5}{|l|}{ Jenis Kelamin } \\
\hline Pria & 48 & $23(47,9)$ & $25(52,1)$ & $1,47 *$ \\
\hline Wanita & 80 & $26(32,5)$ & $54(67,5)$ & $(0,96-2,27)$ \\
\hline \multicolumn{5}{|l|}{ Status Kawin } \\
\hline Kawin & 89 & $37(41,6)$ & $52(58,4)$ & 1,35 \\
\hline Belum kawin/cerai & 39 & $12(30,8)$ & $27(69,2)$ & $(0,79-2,30)$ \\
\hline \multicolumn{5}{|l|}{ Tingkat pendapatan } \\
\hline <UMR Jakarta 2019 & 39 & $18(46,2)$ & $21(53,8)$ & 1,33 \\
\hline 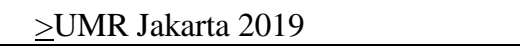 & 89 & $31(34,8)$ & $58(65,2)$ & $(0,85-2,06)$ \\
\hline \multicolumn{5}{|l|}{ Riwayat PJK dalam keluarga } \\
\hline $\mathrm{Ya}$ & 17 & $8(47,1)$ & $9(52,9)$ & 1,27 \\
\hline Tidak & 111 & $41(36,9)$ & $70(63,1)$ & $(0,73-2,23)$ \\
\hline \multicolumn{5}{|l|}{ Riwayat hipertensi dalam keluarga } \\
\hline $\mathrm{Ya}$ & 69 & $27(39,1)$ & $42(60,9)$ & 1,05 \\
\hline Tidak & 59 & $22(37,3)$ & $37(62,7)$ & $(0,67-1,63)$ \\
\hline \multicolumn{5}{|l|}{ Riwayat diabetes dalam keluarga } \\
\hline $\mathrm{Ya}$ & 42 & $15(35,7)$ & $27(64,3)$ & 0,90 \\
\hline Tidak & 86 & $34(39,5)$ & $52(60,5)$ & $(0,56-1,46)$ \\
\hline \multicolumn{5}{|l|}{ Kesehatan mental emosional } \\
\hline Gangguan ringan-sedang, skor 6-15 & 18 & $8(44,4)$ & $10(55,6)$ & 1,20 \\
\hline Tidak terganggu, skor $\leq 5$ & 110 & $41(37,3)$ & $69(62,7)$ & $(0,67-2,11)$ \\
\hline \multicolumn{5}{|l|}{ Aktifitas fisik } \\
\hline Rendah $(<600$ MET $)$ & 46 & $17(37)$ & $29(63)$ & 0,95 \\
\hline Sedang-Tinggi ( $\geq 600$ MET) & 82 & $32(39)$ & $50(61)$ & $(0,60-1,51)$ \\
\hline \multicolumn{5}{|l|}{ Kualitas tidur } \\
\hline Gangguan ringan-sedang, skor 6-14 & 61 & $23(37,7)$ & $38(62,3)$ & 0,97 \\
\hline Tidak terganggu, skor $\leq 5$ & 67 & $26(38,8)$ & $41(61,2)$ & $(0,63-1,51)$ \\
\hline \multicolumn{5}{|l|}{ Tingkat Pengetahuan } \\
\hline Kurang (nilai <75) & 52 & $22(42,3)$ & $30(57,7)$ & 1,20 \\
\hline Baik (nilai $\geq 75$ ) & 76 & $27(35,5)$ & $49(64,5)$ & $(0,77-1,85)$ \\
\hline \multicolumn{5}{|l|}{ Indeks Massa Tubuh (IMT) } \\
\hline Obesitas $\left(>27 \mathrm{~kg} / \mathrm{m}^{2}\right)$ & 59 & $33(55,9)$ & $26(44,1)$ & $1,74^{*}$ \\
\hline Tidak obesitas $\left(\leq 27 \mathrm{~kg} \cdot \mathrm{m}^{2}\right)$ & 69 & $16(23,2)$ & $53(76,8)$ & $(1,27-2,39)$ \\
\hline
\end{tabular}

Keterangan: *hasil temuan signifikan dengan tingkat signifikansi $(\alpha) 0,05$.

Sumber: Data Primer, 2019

Faktor determinan lainnya juga perlu mendapat perhatian jika dikaitkan dengan risiko pra-SM, karena beberapa faktor menunjukkan peningkatan risiko meskipun tidak bermakna secara statistik. Status perkawinan menunjukkan ada peningkatan risiko praSM pada mereka yang berstatus kawin dibandingkan yang belum kawin/cerai (PR: 1,35; 95\% CI: 0,79 - 2,30). Hubungan antara kondisi kesehatan mental dengan kejadian praSM juga terlihat ada peningkatan sebesar 1,20 meskipun tidak bermakna (95\%CI: 0,67 - 
2,11). Selain itu, ada kecenderungan peningkatan risiko pra-SM sebesar 1,2 kali pada mereka yang kurang pengetahuan dibandingkan yang berpengetahuan baik, meskipun hubungan ini tidak bermakna secara statistik (95\%CI: 0,77-1,85). Berdasarkan status kepegawaian memperlihatkan bahwa risiko pra-SM pada kelompok dosen dan tenaga kependidikan tidak berbeda (PR: 1,17; 95\% CI: 0,75-1,81). Variabel kualitas tidur menunjukkan tidak berhubungan dengan pra-SM (PR: 0,97; 95\%CI: 0,63-1,51). Risiko pra-SM juga terlihat rendah (PR: 0,95) pada responden yang memiliki aktifitas rendah dibandingkan dengan mereka yang beraktifitas sedang-tinggi (95\% CI: 0,60-1,51).

Dalam analisis regresi logistik ganda model prediktif, semua variabel independent diikutsertakan dalam analisis multivariat karena merupakan faktor risiko yang secara subtansi (teori/konsep) memiliki keterkaitan dengan kejadian pra-sindrom metabolik. Hasil analisis model lengkap (full model) dicantumkan dalam tabel 4. Hasil menunjukkan bahwa dalam kemaknaan model (dengan batas nilai $p \leq 0,05$ ) masih terdapat variabel yang tidak dapat memberikan kontribusi terhadap hubungannya dengan kejadian pra-SM yaitu: riwayat hipertensi dalam keluarga, riwayat penyakit diabetes dalam keluarga, status kesehatan mental, status perkawinan, aktifitas fisik, kualitas tidur, riwayat penyakit jantung dalam keluarga, tingkat pengetahuan, dan status kepegawaian. Oleh karena itu, variabel tersebut secara satu per satu dikeluarkan dalam analisis yang dimulai dari nilai kemaknaan (nilai $p$ ) yang terbesar.

Tabel 4. Hasil Analisis Regresi Logistik Model Prediktif Lengkap (Full Model)

\begin{tabular}{lccc}
\hline \multicolumn{1}{c}{ Variabel } & Nilai p & Exp $(\boldsymbol{\beta})$ & $\begin{array}{c}\text { 95\% Confidence } \\
\text { interval }\end{array}$ \\
\hline Umur & 0,08 & 2,75 & $0,89-8,52$ \\
\hline Status pegawai & 0,34 & 1,67 & $0,58-4,85$ \\
\hline Jenis kelamin & 0,10 & 2,13 & $0,86-5.30$ \\
\hline Status perkawinan & 0,85 & 0,91 & $0,33-2,46$ \\
\hline Tingkat pendapatan & 0,12 & 2,34 & $0,81-6,74$ \\
\hline Riwayat penyakit jantung dalam keluarga & 0,59 & 1,42 & $0,40-5,09$ \\
\hline Riwayat penyakit hipertensi dalam keluarga & 0,99 & 0,99 & $0,40-2,47$ \\
\hline Riwayat penyakit diabetes dalam keluarga & 0,96 & 0,97 & $0,38-2,51$ \\
\hline Status kesehatan mental & 0,93 & 1,06 & $0,30-3,70$ \\
\hline Aktifitas fisik & 0,70 & 1,19 & $0,49-2,92$ \\
\hline Kualitas tidur & 0,69 & 0,83 & $0,34-2,05$ \\
\hline Tingkar pengetahuan & 0,67 & 1,21 & $0,50-2,93$ \\
\hline Kegemukan (indeks massa tubuh $\left.>27 \mathrm{~kg} / \mathrm{m}^{2}\right)$ & 0,001 & 5,09 & $2,18-11,88$ \\
\hline
\end{tabular}

Sumber: Data Primer, 2019 
Hasil analisis selanjutnya pada tabel 5, memperlihatkan model yang sudah dikurangi dengan variabel yang tidak bermakna secara statistik (reduce model).

Tabel 5. Model Akhir Hasil Analisis Multivariat Untuk Menjelaskan Faktor Determinan Yang Paling Berhubungan Dengan Kejadian Pra-SM.

\begin{tabular}{lcccc}
\hline \multicolumn{1}{c}{ Variabel } & $\boldsymbol{\beta}$ & Nilai $\boldsymbol{p}$ & $\boldsymbol{E x p}(\boldsymbol{\beta})$ & $\begin{array}{c}\mathbf{9 5 \%} \text { Confidence } \\
\text { interval }\end{array}$ \\
\hline Umur & 1,14 & 0,02 & 3,11 & $1,18-8,23$ \\
\hline Jenis kelamin & 0,70 & 0,10 & 2,02 & $0,87-4,67$ \\
\hline Tingkat pendapatan & 0,65 & 0,15 & 1,91 & $0,79-4,65$ \\
\hline Kegemukan (indeks massa tubuh $\left.>27 \mathrm{~kg} / \mathrm{m}^{2}\right)$ & 1,61 & 0,0001 & 5,02 & $2,20-11,47$ \\
\hline Nilai konstanta & $-2,61$ & 0,0001 & 0,07 & \\
\hline$\quad$ Sumber: Data Primer, 2019 & & & &
\end{tabular}

Dalam tabel terlihat bahwa faktor determinan yang paling berhubungan dengan kejadian pra-SM adalah: umur, jenis kelamin, tingkat pendapatan dan kegemukan. Dalam penelitian ini, katagori umur menggunakan batasan umur 35 tahun mengikuti kriteria WHO yaitu kelompok umur dewasa akhir adalah >35 tahun merupakan kelompok umur berisiko untuk berkembangnya masalah kesehatan karena proses degeneratif. Hasil penelitian membuktikan bahwa sebagian besar responden adalah kelompok umur $>35$ tahun yaitu 89 orang dengan proporsi pra-SM lebih banyak $(44,9 \%)$ daripada mereka yang berumur $\leq 35$ tahun. Prevalens rasio sebesar 1,95 menunjukkan bahwa mereka yang berumur > 35 tahun berisiko hampir 2 kali lebih tinggi untuk terjadinya pra-SM.

Hasil ini sejalan dengan penelitian Lin, Y. C., dkk (2010) yang menunjukkan bahwa responden penderita SM rata-rata berumur >33 tahun dengan jumlah komponen kriteria $\mathrm{SM} \geq 2$ indikator (sesuai dengan kriteria pra-SM). Pada responden kelompok dewasa usia paruh baya yang memiliki satu atau dua kriteria SM masing-masing memiliki risiko 2,8 kali dan 7,3 kali untuk berkembang menjadi SM dalam lima tahun, dibandingkan mereka yang tidak memiliki kriteria SM (Lin et al., 2010).

Pada umumnya peningkatan SM akan mencapai puncaknya pada usia 50-an. Faktor risiko metabolik muncul pada waktu yang berbeda sepanjang hidup dan biasanya berkembang atau memburuk pada usia lanjut. Gangguan metabolik dapat bertahan sepanjang hidup, mungkin masih laten sampai faktor lain turut berkontribusi terhadap SM, seperti: kenaikan berat badan yang umum terjadi pada usia pertengahan. Dislipidemia dan hipertensi sistolik/diastolik biasanya muncul di usia pertengahan. Pertambahan berat badan akan lebih memungkinkan menjadi faktor risiko metabolik (Grundy, 2018). 
Menurut peneliti, penilaian (skrining) risiko berkembangnya SM sangat diperlukan untuk semua orang dewasa yang memiliki kondisi pra-SM dan juga mereka yang berisiko tetapi belum memenuhi kriteria pra-SM pada saat pemeriksaan. Faktor umur merupakan salah satu faktor utama yang sering dinilai dalam penelitian kesehatan karena bertambahnya umur dapat meningkatkan risiko penyakit degeneratif.

Variabel jenis kelamin berhubungan dengan kejadian pra-SM, hasil ini sejalan dengan penelitian yang dilakukan pada para pekerja di Taiwan, sekitar $80,6 \%$ pekerja berjenis kelamin laki-laki dan sekitar 58,6\% diantara mereka memiliki sekurang-kurangnya satu atau dua kriteria pra-SM (Lin et al., 2010).

Penelitian lain memperlihatkan hasil yang berbeda jika faktor umur dan jenis kelamin dilihat secara bersama-sama dalam hubungannya dengan perkembangan SM. Pembuktian berupa prevalens SM yang meningkat terjadi pada wanita umur >60 tahun yaitu sebesar 54\% dibandingkan pada laki-laki. Perbedaan tersebut karena pada wanita postmenopause, akumulasi lemak meningkat dengan cepat, selanjutnya penurunan estrogen merangsang adiposit hipertrofi dan disfungi adiposit yang juga mendukung akumulasi lemak viseral secara berlebihan. Hal ini meningkatkan obesitas abdominal dan status postmenopause mengarah pada peningkatan prevalensi SM (D G. Karalis, Denise A, 2018).

Perbedaan gender pada SM berkontribusi pada penyakit kardiovaskular dan diabetes melitus tipe 2. Fakta epidemiologis menunjukkan ada peningkatan insiden penyakit jantung koroner pada wanita khususnya pada periode postmenopause. Interaksi antara berbagai faktor risiko penyakit kardiovaskuler dengan hormon dapat berperan dalam perkembangan SM pada wanita (Bantas et al., 2012).

Peneliti berpendapat bahwa faktor jenis kelamin dapat memberikan kontribusi yang berbeda dalam memprediksi kejadian pra-SM di lingkungan pekerja perkantoran seperti profesi dosen dan tenaga kependidikan. Ketidaksetaraan gender pada status kesehatan merefleksikan ketidaksamaan faktor biologis dan sosial terkait jenis kelamin serta interaksi dari kedua faktor tersebut. Oleh karena itu fokus intervensi pada individu pekerja dapat berbeda dengan mempertimbangkan faktor jenis kelamin.

Faktor tingkat pendapatan merupakan proksi dari status ekonomi individu yang penting dan dapat mempengaruhi kondisi kesehatan khususnya pada penderita penyakit kronis terutama dalam memenuhi kebutuhan akses pelayanan kesehatan. Sistem pelayanan 
kesehatan mempunyai peran penting dalam pencegahan, deteksi dini dan skrining kesehatan dengan harapan dapat mengurangi biaya layanan dan beban mental penderitanya. Perilaku seseorang dalam minat pencarian pelayanan kesehatan dapat dipengaruhi oleh faktor sosial ekonomi. Pada mereka yang tingkat pendapatannya lebih tinggi berhubungan dengan prevalensi morbiditas dan mortalitas yang lebih rendah (Foraker et al., 2011).

Hasil penelitian memperlihatkan bahwa tingkat pendapatan keluarga responden per bulan dengan indikator UMK DKI Jakarta tahun 2019 (Rp. 3.940.973) menunjukkan jumlah yang lebih besar pada katagori pendapatan $\geq$ UMK yaitu 89 orang dari 128 responden. Namun, proposrsi pra-SM lebih banyak terjadi pada mereka yang memiliki pendapatan $<$ UMK (46,2\%). Perbedaan proporsi ini tidak menunjukkan adanya hubungan yang bermakna secara statistik dengan PR: 1,33 dan 95\% CI: 0,85 - 2,06.

Penelitian ini sejalan dengan penelitian yang dilakukan di Korea terhadap pelayanan kesehatan milik pemerintah dan swasta. Hasilnya menunjukkan ada hubungan antara faktor sosial ekonomi dengan prevalensi SM. Prevalensi SM berbeda signifikan berdasarkan tingkat pendapatan, OR kejadian SM pada mereka yang berpenghasilan $>10$ juta KRW (Mata uang Won Korea) per bulan adalah lebih rendah yaitu sebesar 0,727 ( $p$ $<0,01)$ dibandingkan dengan mereka yang berpenghasilan $<5$ juta KRW per bulan. Pada penderita SM telah dibuktikan bahwa status sosial ekonomi yang baik berhubungan dengan perilaku yang lebih aktif dalam perawatan dan pencegahan kesehatan. Oleh karena itu, status sosial ekonomi dapat mempengaruhi kesehatan individu dan pencegahan komplikasi khususnya penyakit kronis (Kim et al., 2018).

Dalam lingkup populasi pekerja di Universitas MH. Thamrin baik sebagai dosen maupun tenaga kependidikan, tingkat pendapatan merupakan faktor penting dalam pemenuhan kebutuhan kesehatan. Adanya jaminan asuransi kesehatan (BPJS Kesehatan) hingga saat ini belum dapat menjamin kepuasaan akan layanan kesehatan. Intervensi pencegahan primer yang berfokus pada perbaikan gaya hidup sehat di lingkungan kampus harus menjadi target utama dalam penanganan secara dini di lingkungan kampus.

Faktor obesitas terbukti memiliki peran meningkatkan risiko pra-SM. Hasil penelitian menunjukkan indeks massa tubuh memiliki distribusi yang berbeda terhadap kejadian pra-SM. Proporsi pra-SM lebih banyak pada mereka yang mengalami obesitas (IMT >27 $\mathrm{kg} / \mathrm{m}^{2}$ ) yaitu sebesar $55,9 \%$ dibandingkan dengan mereka yang tidak obesitas (IMT $\leq 27$ 
$\mathrm{kg} / \mathrm{m}^{2}$ ) yaitu $23,2 \%$. Perbedaan proporsi tersebut menghasilkan nilai risiko pra-SM sebesar 1,74 kali lebih tinggi pada mereka yang mengalami obesitas.

Obesitas terjadi ketika penumpukan lemak tubuh relatif tinggi, ditandai dengan IMT $>27$ $\mathrm{kg} / \mathrm{m}^{2}$. Meningkatnya prevalensi obesitas dan penyakit penyerta dapat meningkatkan biaya pelayanan kesehatan (Ozmen et al., 2009). Pendapat lain yang sejalan dengan hasil penelitian ini menjelaskan bahwa SM paling sering terjadi pada orang dengan obesitas (IMT $\geq 30 \mathrm{~kg} / \mathrm{m}^{2}$ ), dibandingkan orang overweight (IMT 25-29,9 kg/m ${ }^{2}$ ) dan relatif jarang pada individu dengan berat badan normal. Penderita obesitas abdominal sangat rentan untuk mengalami SM (Grundy, 2018).

Peneliti berpendapat bahwa distribusi responden yang mengalami obesitas sebesar $46 \%$ (59 dari 128 responden) merupakan proporsi yang cukup tinggi untuk menjadi faktor prediksi berkembangnya pra-SM. Oleh karena itu, hasil penelitian ini dapat pula menjadi data pendukung untuk merencanakan program kesehatan di lingkungan kampus.

Penelitian ini memiliki keterbatasan dari besar sampel (respon rate $71 \%$ ) yang berdampak pada tingkat kemaknaan statistik sehingga perlu menjadi perhatian bagi pembaca agar tidak keliru dalam interpretasinya. Namun, terdapat hal lain yang menjadi keunggulan penelitian yaitu bahwa untuk menegakkan diagnosis pra-SM peneliti menggunakan indikator obesitas sentral dan tekanan darah yang hasil pengukurannya dapat dipercaya serta cukup valid sehingga kemungkinan bias dapat diminimalkan.

\section{SIMPULAN}

Kesimpulan hasil penelitian adalah bahwa kriteria diagnosis pra-SM merupakan bentuk skrining awal yang valid dan hasilnya dapat memberikan informasi untuk merencanakan suatu program kesehatan di lingkungan kampus. Faktor determinan yang memiliki hubungan bermakna terhadap kejadian pra-SM adalah: umur, kegemukan, jenis kelamin, dan tingkat pendapatan. Faktor lain yang memiliki kontribusi terhadap pra-SM namun belum terbukti bermakna dalam analisis statistik adalah: status kepegawaian, status perkawinan, riwayat penyakit kronis dalam keluarga, status kesehatan mental, kualitas tidur, aktifitas fisik dan tingkat pengetahuan. Hal ini memerlukan penggalian informasi terhadap faktor tersebut secara lebih mendalam dan waktu khusus untuk menghindari ketergesaan dalam menjawab atau memberikan informasi. 
Rekomendasi yang dapat diberikan dari hasil penelitian ini khususnya untuk institusi adalah perlunya dukungan institusi untuk pengembangan program skrining berkelanjutan sehingga temuan kasus pra-SM dapat menjadi dasar upaya pencegahan penyakit tidak menular. Untuk peneliti sekanjutnya, dapat mengembangkan metode campuran (kualitatif dan kuantitatif) sehingga penelitian menjadi lebih kaya informasi, khususnya yang memerlukan penggalian mendalam terhadap variabel yang bersifat subyektif seperti status kesehatan mental, kualitas tidur dan perilaku kesehatan.

\section{UCAPAN TERIMA KASIH}

Ucapan terima kasih disampaikan kepada pimpinan Universitas MH. Thamrin khususnya jajaran Rektorat dan LPPM yang telah memberi kesempatan, mendukung dari aspek teknis dan pendanaan sehingga penelitian ini dapat dilaksanakan. Seluruh responden penelitian yang telah berpartisipasi dalam penelitian semoga hasil penelitian ini dapat memberikan manfaat untuk mengenali secara dini kondisi pra-SM sehingga upaya pencegahan dan pengendalian masalah penyakit tidak menular dapat dilakukan mulai dari tingkat individu sampai institusi.

\section{REFERENSI}

1. A. Alamri, F., A. Amer, S., Almubarak, A., \& Alanazi, H. (2019). Sleep Quality among Healthcare Providers; In Riyadh, 2019. International Journal of Medical Science and Clinical Invention, 6(5), 4438-4448. https://doi.org/10.18535/ijmsci/ v6i5.03

2. Bantas, K., Yoseph, H. K., \& Moelyono, B. (2012). Perbedaan Gender pada Kejadian Sindrom Metabolik pada Penduduk Perkotaan di Indonesia. Kesmas: National Public Health Journal, 7(5), 219. https://doi.org/10.21109/kesmas.v7i5.44

3. Chackrewarthy, S., Gunasekera, D., Pathmeswaren, A., Wijekoon, C. N., Ranawaka, U. K., Kato, N., Takeuchi, F., \& Wickremasinghe, A. R. (2013). A Comparison between Revised NCEP ATP III and IDF Definitions in Diagnosing Metabolic Syndrome in an Urban Sri Lankan Population: The Ragama Health Study. ISRN Endocrinology, 2013, 1-7. https://doi.org/10.1155/2013/320176

4. Church, T. S., Thomas, D. M., Tudor-Locke, C., Katzmarzyk, P. T., Earnest, C. P., Rodarte, R. Q., Martin, C. K., Blair, S. N., \& Bouchard, C. (2011). Trends over 5 
decades in US occupation-related physical activity and their associations with obesity. In PloS one (Vol. 6, Issue 5). Public Library of Science.

5. D G. Karalis, Denise A, S. Y. N. (2018). Clinical feature: gender differences in the diagnosis and treatment of the metabolic syndrome. National Lipid Association, April. https://www.lipid.org/node/1448

6. Foraker, R. E., Rose, K. M., Suchindran, C. M., Chang, P. P., McNeill, A. M., \& Rosamond, W. D. (2011). Socioeconomic status, medicaid coverage, clinical comorbidity, and rehospitalization or death after an incident heart failure hospitalization atherosclerosis risk in communities cohort (1987 to 2004). Circulation: Heart Failure, 4(3), 308-316. https://doi.org/10.1161/ CIRCHEARTFAILURE. 110.959031

7. Grundy, S. (2018). Metabolic Syndrome. In E. Bonora \& R. A. DeFronzo (Eds.), Diabetes Complications, Comorbidities and Related Disorders (pp. 71-107). Springer Switzerland.

8. Jeong, H. S. (2018). The relationship between workplace environment and metabolic syndrome. International Journal of Occupational and Environmental Medicine, 9(4), 176-183. https://doi.org/10.15171/ijoem.2018.1346

9. Johnson, P., Turner, L., Carter, M., Kelly, R., \& Ewell, P. J. (2015). Metabolic syndrome prevalence and correlates in a worksite wellness program. Workplace Health and Safety, 63(6), 245-252. https://doi.org/10.1177/2165079915576920

10. Kemenkes RI. (2018). Laporan Nasional Riset Kesehatan Dasar. Kementerian Kesehatan RI, 1-582.

11. Kim, Y. H., Kim, H., \& Jee, H. (2018). Effects of socioeconomic status, health behavior, and physical activity on the prevalence of metabolic syndrome. Journal of Exercise Rehabilitation, 14(2), 183-191. https://doi.org/10.12965/jer.1836074.037

12. Lin, Y. C., Chen, J. D., Lo, S. H., \& Chen, P. C. (2010). Worksite health screening programs for predicting the development of Metabolic Syndrome in middle-aged employees: A five-year follow-up study. BMC Public Health, 10. https://doi.org/10.1186/1471-2458-10-747

13. Negi, P. C., Sondhi, S., Merwaha, R., \& Asotra, S. (2019). Prevalence and risk determinants of metabolic syndrome in obese worksite workers in hill city of Himachal Pradesh, India. Indian Heart Journal, 71(1), 45-51. 
https://doi.org/10.1016/j.ihj.2019.01.001

14. Ozmen, B., Demet, M. M., Guclu, F., Kafesciler, S., Aydemir, O., \& Hekimsoy Z Dr. Bilgin Ozmen, P. B. N. D. A.-I. T. E. mail bilozmen yahoo com. (2009). Metabolic syndrome and health-related quality-of-life in obese women. IJCP. 2009 Apr; 19(11): 30-36, January.

15. Shuto, H., Shuto, C., Inoue, T., Nishikata, H., \& Tokutake, E. (2015). Assesment of Waist Circumferene Index A New Screening Parameter for Pre-Metabolic Syndrome. J Health Edu Res Dev, 3.

16. Tan, C., Sasagawa, Y., Kamo, K. ichi, Kukitsu, T., Noda, S., Ishikawa, K., Yamauchi, N., Saikawa, T., Noro, T., Nakamura, H., Takahashi, F., Sata, F., Tada, M., \& Kokai, Y. (2016). Evaluation of the Japanese Metabolic Syndrome Risk Score (JAMRISC): a newly developed questionnaire used as a screening tool for diagnosing metabolic syndrome and insulin resistance in Japan. Environmental Health and Preventive Medicine, 21(6), 470-479. https://doi.org/10.1007/s12199-016-0568-5

17. WHO. (2018). Non Communicable Diseases. https://www.who.int 